\title{
ARARUNA: IDENTIDADE CONSTRUÍDA E SIGNIGIFACADOS REVELADOS NO ESPAÇO VIVIDO
}

\author{
Josenildo da Silva Martins' e Evaneide Maria de Melo ${ }^{2}$ \\ 'Universidade Federal do Rio Grande do Norte \\ ${ }^{2}$ Instituto Federal do Rio Grande do Norte - Campus Caicó \\ Josenildomartins.forever@hotmail.com ${ }^{1}$, evaneide.melo@ifrn.edu.br ${ }^{2}$
}

Artigo submetido em janeiro/2013 e aceito em dezembro/2013

\section{RESUMO}

Este artigo é evidência dos estudos geográficos realizados através da análise da relação espaço-cultura. No Brasil, é a partir de 1990 que a produção começa a ser evidente. Este trabalho contribui para essa evidência, visto que, pouco mais de duas décadas depois, apreende parte significativa dessas produções, quer seja no contexto nacional, quer seja no internacional, para analisar a dimensão cultural do espaço vivido pelo grupo Araruna. A representação espacial da realidade vivida pelo grupo se apresenta na forma de monumento, forma espacial traduzida na sede do grupo, que materializa parte de sua cultura e constitui base de sua identidade.

PALAVRAS-CHAVE: Grupo Araruna, Espaço Vivido, Identidade, Significados.

\section{ARARUNA: CONSTRUCTED IDENTITY AND MEANINGS REVEALED IN THE SPACE EXPERIENCED}

\section{ABSTRACT}

This article is evidence from the geographical studies conducted by analyzing the relationship space-culture. In Brazil, it is since 1990 that production begins to be evident. This study adds to this evidence since a little over two decades later it apprehends a significant part of these productions both in the national and international contexts so as to analyze the cultural dimension of space experienced by the "Araruna" group. The spatial representation of the reality experienced by the group performs in the form of monuments, a spatial form translated at the headquarters of the group, which comprises part of their culture and their identity.

KEYWORDS: Araruna Group, Experienced Space, Identity, Meanings. 


\section{ARARUNA: IDENTIDADE CONSTRUÍDA E SIGNIGIFACADOS REVELADOS NO ESPAÇO VIVIDO}

\section{INTRODUÇÃO}

O estudo em tela apresenta como objeto de pesquisa o grupo cultural Araruna que representa parcela importante do universo cultural norteriograndense. Organizado oficialmente a partir de 1956, com estatuto registrado e sede própria (GURGEL, 2001; GURGEL, 1982), o grupo tem sua eminência na Zona Leste da cidade do Natal. Sua sede, monumento pelo qual parte da cultura ganha materialidade no espaço, está localizada na Rua Miramar, 173, no bairro das Rocas. Seus integrantes

[...] apresentam-se normalmente com oito e dez pares de dançarino [...] que executam, ao estilo das danças aristocráticas de salas, diversos números, alguns com denominação tipicamente folclórica, outras não. [...] os cavalheiros usam casaca e cartola. As damas, longos vestidos de saia rodada. Tudo ao estilo dos Aristocratas do século passado (GURGEL, 1982, p. 33).

Para tanto, este artigo apresenta como objetivo analisar a dimensão cultural do espaço vivido deste grupo, expressa na manifestação de sua cultura e traduzida em suas (i) materialidades. A ênfase é dada a análise dos significados atribuídos e da identidade construída no locus do vivido pelo grupo, representada, em grande medida, na forma espacial Araruna, monumento pelo qual parte da manifestação do grupo ganha materialidade no espaço.

O Estudo traz à baila reflexões e compilações de pesquisas documental, bibliográfica e de campo, realizadas entre anos 2011 e 2012, no âmbito de pesquisa monográfica sob orientação da Profa Dra. Evaneide Maria de Melo e no ano de 2013 se torna, efetivamente, base do Projeto de Mestrado para pesquisa na dissertação sob orientação da Profa. Dra Maria Helena Braga e Vaz da Costa.

A ideia é apreender as teias tecidas do complexo conjunto de valores, imaginários, representações em meio aos significados atribuídos e a identidade construída na ação do grupo cultural exercida espacialmente, para revelar a dimensão cultural do espaço. Logo, mostrando a essência das experiências vividas espacialmente. Dessa forma, o trabalho traduz uma reflexão do "papel que o espaço e o meio têm na vida dos homens, sobre o sentido que eles lhes dão e sobre a maneira pela qual eles os utilizam para melhor se compreenderem e construírem seu ser profundo" (CLAVAL, 2010, p. 89-90).

Nessa perspectiva, o estudo lança um olhar fenomenológico como método de abrangência sobre o objeto de estudo e torna-se original na trajetória geográfica, quer no âmbito local, quer num contexto mais amplo, sobretudo, pela dimensão cultural que rebate na constituição dos espaços. Isso porque a ausência de bibliografia permite inferir que inexistem trabalhos geográficos no âmbito do grupo Araruna. O que se torna de extrema importância uma vez que "o mundo contemporâneo vive um enorme descompasso entre o que ocorre em sua dimensão concreta, material, e sua dimensão ou esfera cultural, no sentido mais amplo do 'simbólico'”' (HAESBAERT, 2006).

A opção por esse desafio foi motivada pelas observações que evidenciam a ausência de um olhar geográfico sobre este grupo no âmbito da dimensão cultural de seu espaço, uma vez que tem-se na ciência geográfica um potencial teórico-metodológico suficiente para analisá-lo. 
Pois, apesar da grande relevância, observa-se que as investigações a respeito inexistem, fazendo com que o trabalho em tela constitua-se em importante fonte de pesquisas acadêmicas e uma forma de registro e reconhecimento a um grupo tão autêntico na cultura popular potiguar.

O obstáculo epistemológico (BACHELARD, 1996) que mobiliza esta pesquisa está expresso no fato de que por muito tempo não se visualizou, não era de interesse ou desprezou-se o estudo sobre a dimensão cultural do espaço deste. Isto porque, as alusões feitas verificaram sua natureza histórico-folclórica (CASCUDO, 1954); (NOGUEIRA, 1978); (GURGEL, 1982) (GURGEL, 2001); (SESC/RN, 2008) e patrimonial (MACEDO, 2006a; 2006b). Além disso, entende-se que "sem a devida contextualização, as histórias passadas de pessoas comuns correm o risco de permanecerem só isso: histórias" (COMARROFF E COMARROFF, 2010, p. 21). É evidente que tais reflexões críticas são provisórias, uma vez que permeia o obstáculo da pesquisa em tela.

Pensando assim, a ausência que atesta a lacuna de conhecimentos construídos e/ou sistematizados sobre a dimensão espacial do grupo - experiências do vivido, significados atribuído, identidade construída - permite levantar um questionamento chave: qual a dimensão cultural do espaço vivido do grupo Araruna? Seguido de um conjunto de indagações que funcionaram como o fio condutor da pesquisa, qual seja: que significados são construídos/atribuídos pelo grupo ao seu espaço vivido? Que formas de identificação identitária ele constrói? Que especialidades ele apresenta? Este fio pressupõe a hipótese de que a dimensão cultural do espaço vivido pelo grupo cumpre fundamental papel na construção de sua identidade e que esse grupo significa o espaço the atribuindo valores e sentimentos e povoando-o de memórias e experiências próprias de seu imaginário e constituidores de suas realidades vividas espacialmente.

\section{PROCEDIMENTOS METODOLÓGICOS}

No contexto da pesquisa do tipo qualitativa manifestada nas facetas bibliográfica, documental e de campo, a metodologia adotada deu-se a partir de três momentos significativos, apresentando, dentre as técnicas de pesquisa que validam o trabalho acadêmico:

I. Levantamento, leitura, fichamento e sistematização de produções bibliográficas no âmbito do tema em análise;

II. Coleta, organização, análise e sistematização de dados secundários (pesquisa documental de fonte primária e secundária) junto à Fundação Cultural Capitania das Artes (FUNCARTE), Ministério Público do Rio Grande do Norte (MPRN), Secretaria Extraordinária de Cultura do Rio Grande do Norte (SEACRN);

III. Trabalho de campo realizado junto ao grupo e traduzido nas técnicas de Observação, Entrevista Semi-estruturada e no método procedimental Etnográfico, que abarquem as peculiaridades mais pertinentes ao estudo e sejam permeadas pelo Registro Fotográfico.

No primeiro procedimento, o desenvolvimento deu-se a partir de material já elaborado (livros, artigos científicos) sendo que sua principal vantagem "reside no fato de permitir ao investigador a cobertura de uma gama de fenômenos muito mais ampla do que aquela que poderia pesquisar diretamente" (GIL, 1999, P. 65). 
No segundo caso, a Pesquisa Documental foi predominante uma vez que ela “(...) vale-se de materiais que não receberam ainda um tratamento, ou que ainda podem ser reelaborados de acordo com objetivos da pesquisa" (GIL, 1999, P. 66).

Já no terceiro caso, a Observação, por exemplo, como técnica de coleta de dados, se fez importante uma vez que contribuiu também para as etnografias. Esse procedimento é compreendido como "uma técnica de coleta de dados para conseguir informações utilizando os sentidos na obtenção de determinados aspectos da realidade" (MARCONI; LAKATOS, 2004, p. 275).

Quanto à técnica de Entrevista, ela foi realizada junto aos integrantes do grupo, observando como eles se veem como sujeitos desse processo, isto é, a participação ativa do grupo na construção da ação. Seu caráter foi do tipo semiestruturada. De acordo com May (2004, p. 149) ela é caracterizada por ter um "caráter aberto", isto é, o entrevistado responde as perguntas solicitadas dentro de sua concepção, mesmo assim, o pesquisador não deve perder de vista o seu foco.

Nos procedimentos etnográficos, utilizou-se como referencial predominante as ideias de Geertz (1978) e Malinowski (1978). Para esse primeiro,

em etnografia, o dever da teoria é fornecer um vocabulário no qual possa ser expresso o que o ato simbólico tem a dizer sobre ele mesmo - isto é, sobre o papel da cultura na vida humana (GEERTZ, 1978, p. 38).

Para o segundo, "o recurso para o etnógrafo é coletar dados concretos sobre todos os fatos observados e através disso formular as interferências gerais" (MALINOWSKI, 1978, p. 24). Mais ainda, "devemos não só anotar os acontecimentos e detalhes ditados pelos costumes e pela tradição como pertencentes à própria essência do ato, mas também registrar, [...] as atitudes de atores e espectadores, uma após as outras" (MALINOWSKI, 1978, p. 31).

Diante desses procedimentos, pode-se então afirmar, parafraseando Marconi e Lakatos (2004), que essa metodologia qualitativa preocupou-se em analisar aspectos mais profundos do grupo e de seu espaço vivido, atentando para a constituição da dimensão cultural do espaço. Dessa forma, teve-se então procedimentos fundamentais para analisar o grupo e apreender o "ponto de vista" deste, seus relacionamentos com o espaço, sua visão de seu mundo (MALINOWSKI, 1978).

Sendo que, para isso, o estudo lança um olhar fenomenológico como método de abrangência sobre o objeto de estudo. Para Relph (1988, p.1), "fenomenologia tem a ver com princípios, com as origens do significado e da experiência". Assim infere-se que com essa acepção se faz possível e viável a dissertação ao passo que as acepções que se constrói aqui sobre tal, perpassam os procedimentos de descrição, análise e reflexão dos elementos sociais e suas formas espaciais, enquanto (i) materialidades da cultura, povoados de significados e experiências e de base identitária.

Para Husserl (1982) fenomenologia é a doutrina universal das essências, em que se integra a ciência da essência do conhecimento. Para ele, os fenômenos da fenomenologia são os manifestados pelas vivências na consciência e sua capacidade imanente de outorgar sentido às coisas enquanto puro pensado. Dessa forma, comunga-se com ambos para respaldar o estudo em tela. 


\title{
3 O GRUPO E A MANIFESTAÇÃO CULTURAL ARARUNA
}

O grupo cultural Araruna foi criado pelo Mestre Cornélio Campina da Silva (1908-2008) folclorista e incentivador da cultura popular potiguar. Foi também um homem responsável e de tamanha abnegação em divulgar e conservar valores, mitos, memória e traços culturais locais expresso, principalmente, por meio do Araruna.

\begin{abstract}
Sua história de vida se confunde com a da criação e permanência da sua amada e fiel Sociedade de Danças Antigas e Semi-Desaparecidas Araruna, relação que se estabelece desde os anos de 1940. Foi dos festejos juninos vivenciados na infância e adolescência que mestre Cornélio trouxe a sua "quadrilha" para o bairro das Rocas, e esta logo tomou o corpo e a forma de uma sociedade de danças e músicas antigas, com pares elegantemente vestidos e educados, se constituindo hoje um justo motivo de orgulho para o folclore potiguar (SESC/RN, 2008, p. 40).
\end{abstract}

Hoje, de sete a doze casais de trabalhadores se reúnem para executar velhas danças. Estes formam o grupo Araruna e juntos executam danças que já estiveram nos melhores salões da chamada aristocracia do passado, hoje em desuso. Nesse sentido, para Vicente (1998, p.13), "falar deste grupo como manifestação cultural do nosso Estado, é reviver um tempo que não volta mais".

O grupo manifesta-se num arranjo espacial no qual os integrantes se distribuem no espaço em forma circular. No círculo, as damas na posição de fora e os cavalheiros por dentro (Figura 1) executam cada coreografia particular às músicas, ao som instrumental da sanfona e do pandeiro.

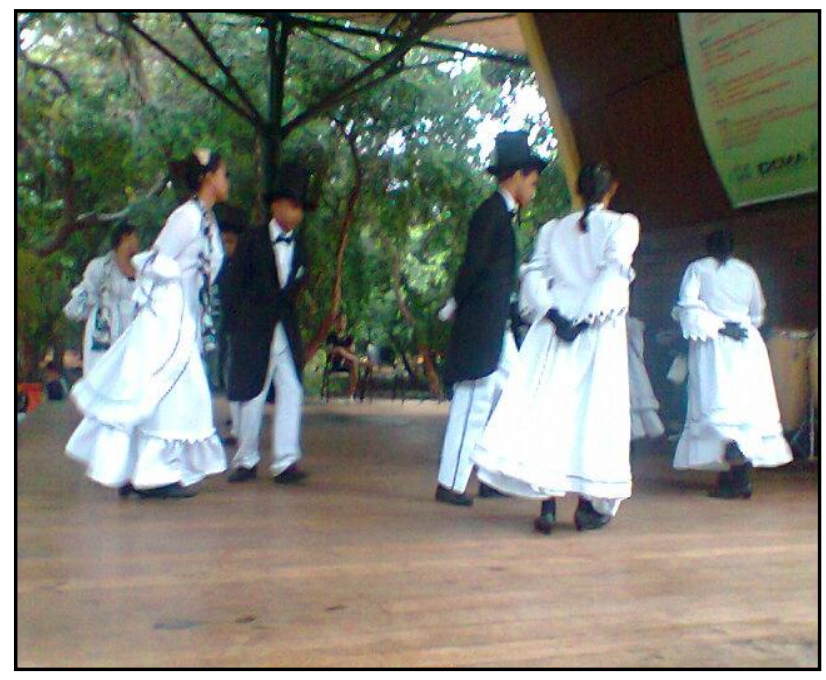

Figura 1 - Manifestação do grupo Araruna no Parque das Dunas, Natal/RN. Fonte: Martins (2011)

Atentado para a figura anteposta é possível observar os homens vestidos de longos fraques pretos, acompanhado de gravata borboleta e sapatos sociais de mesma cor. $E$, calça, camisa social e luvas de cor branca. Já as mulheres, com longos vestidos brancos de saia rodada e mangas compridas, bem abertas nas proximidades da mão (um estilo Boca de Sino), com detalhes desenhando a borda das costuras e enfeitando-as com fitas e rendas nas barras, sapatos pretos e cabelos presos. Também usando luvas, sendo que nelas a cor é preta. Usando também 
bastantes assessórios. Dessa forma, configurando o que outrora era apresentado solenemente nos bailes dos salões da aristocracia.

Dentre as danças executadas que ainda hoje, mesmo em desuso, compõem a apresentação do grupo, significando sua originalidade e fidelidade à tradição, pode-se destacar os seguintes números: Araruna, Besouro, Camaleão, Caranguejo, Jararaca, Maria Rita, Mazurca, Miudinho, Mulher Rendeira, O Bode, Pau-pereiro, Polca, Quadrilha, Rancheira, Sete Rodas, Valsa, Xote.

\section{IDENTIDADE E SIGNIFICADOS NO GRUPO ARARUNA: EXPERIÊNCIAS DO VIVIDO}

Por tratar da dimensão cultural do espaço respeitando a tríade espaço-tempo-vivência no grupo Araruna, a categoria analítica que mais traduz o entendimento desse trabalho é a que rebate a identidade no locus do espaço vivido e das experiências construídas. Assim, partilha-se com Claval (2010) a ideia da qual se tem que:

As identidades se associam ao espaço, elas se baseiam nas lembranças divididas, nos lugares visitados por todos, nos monumentos que refrescam a memória dos grandes momentos do passado, nos símbolos gravados nas pedras das esculturas ou nas inscrições (CLAVAL, 2010, p.107).

Quanto aos significados construídos e revelados, sente-se a necessidade de trazê-los às reflexões e análises nesse momento, devido ao fato de que para Corrêa e Rosendahl (2010, p. 17) "os significados das diversas práticas espaciais associadas ao cotidiano, envolvendo as coisas correntes, e as manifestações menos frequentes ou periódicas estão, com raras exceções, a serem evidenciados pelos geógrafos brasileiros".

Significado entendido, nessa perspectiva, como "uma relação entre uma configuração ou signo e um observador" (BARTH, 2000, p. 128), que direcionará o olhar para a ligação entre a manifestação cultural Araruna e os atores do grupo cultural que por meio de sua cultura se expressam. Isso porque, considerando o significado como "uma relação", será dado, necessariamente, mais atenção ao contexto e à práxis do grupo e sua manifestação.

Dessa forma, é elucidada a importância da compreensão da dimensão cultural do espaço vivido do grupo, objeto de estudo, mediante interações socioculturais da realidade vivida espacialmente. Isso porque, "é na perspectiva da vivência e da experiência que a interação pode ser convertida em objeto, deflagrando processos identitários que estabeleçam a diferença como fundante" (SERPA, 2012, p. 40).

Essa identidade pode significar a maneira pela qual o grupo se expressa e se identifica no o espaço e esse espaço, por sua vez, externaliza essa identificação imprimida nele. Seja nos elementos culturais materiais, no sentido das formas, seja imaterial, no sentido dos valores e significados. Seja na fala, na dança, nos cânticos do grupo, seja na (re) construção e conto de sua história, de forma que o caracterize como representação de vida, de cotidiano, com a função de identificar o grupo e seu espaço e o espaço identificá-lo, gerando assim uma dialética entre espaço e identidade na práxis da prática social Araruna. 
Identidade essa que caracteriza, diferencia e individualiza, mas que não generaliza o grupo. Expressa na cultura, imprimida no espaço e traduzida no patrimônio material e imaterial que, por agregar elementos de um processo histórico e cultural construído no espaço vivido, é também dinâmica e flexível, está em constante (re) construção, com existência física (forma espacial, grupo) e abstrata (valores, significados, imaginários) e em permanente resignificação.

Nessa perspectiva, comunga-se com Serpa (2012) a ideai de que:

Se, em um primeiro momento, a identidade era relacionada em sua dimensão espacial ao território nacional e à nacionalidade, no momento atual as "identidades" parecem apontar para a necessidade de pertencimento a um "lugar" no mundo; também apontam para a ideia de espaços vividos, articulando recortes e escalas diversas, de acordo com os objetivos diferenciados de indivíduos e grupos (SERPA, 2012, p. 41).

É nesse último âmbito que rebate-se o estudo em tela. De forma que se lance à compreensão desta identidade como um processo, defendendo-se a ideia também de que sua "construção é sempre provisória, inacabada e instável, tem caráter processual e articula diferentes recortes a partir dos lugares de sua 'enunciação' (ou autoproclamação)" (SERPA, 2012, p.41), traduzida no espaço vivido do grupo e materializado no monumento Araruna e nos elementos de significação desse espaço (Ver Figura 2).

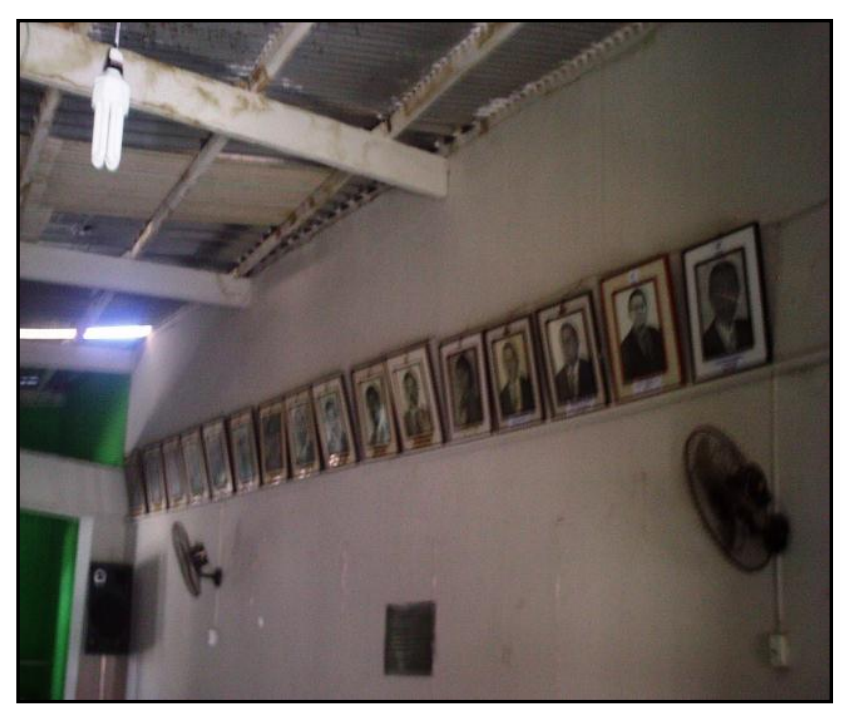

Figura 2 - Interior do monumento Araruna. Fonte: Martins (2011)

A figura anteposta apresenta o interior do monumento Araruna. Na parede, quadros com fotografia daqueles que construíram a história no seu princípio, a exemplo do Mestre Cornélio e do saudoso Luís da Câmara Cascudo. Lugar Simbólico, a sede traduz a memória e revela a identificação do grupo, que vem desde sua fundação - na primeira geração com o Mestre Campina, passando pela segunda geração, dos filhos e amigos dos integrantes do grupo, e a terceira e atual geração, uma mescla dos primeiros dançantes, com os filhos e amigos destes, além dos netos do Mestre.

O que de forma precisa revela o porquê da tradição esta tão evidente no espaço vivido do grupo e revelado no discurso prazeroso dos sujeitos produtores, quando indagados sobre o significado que este espaço de vivência lhes remete: "A representação, a memória do Mestre Cornélio Campina. Relembrança dos velhos momentos! As fotografias na parede trazem também 
isso" (Informação verbal) ${ }^{1}$. "Uma oportunidade! Um espaço para nossos ensaios, conversas, brincadeiras" (Informação verbal) ${ }^{2}$.

Nesse sentido, "[...] as relações do homem com o espaço não constituem um feixe de dados imanentes ou inatos; combinam-se numa experiência vivida que, de acordo com as idades da vida, se forma, se estrutura, se desfaz" (FRÉMONT, 1980, p. 23). Dessa forma, acredita-se que no caso do Araruna essa acepção é válida uma vez que as relações estabelecida são é também históricas, dinâmicas e flexíveis no tempo e no espaço.

Nessa perspectiva, a voz dos atores sociais que constituem o grupo Araruna são trazidas à baila para revelar a realidade cultural do grupo por meio da apresentação do diálogo evidenciado em etnografias e entrevistas realizadas no transcorrer do período das pesquisas, no qual se fez preciso a penetração do geógrafo no espaço dos sujeitos objeto do estudo. Salientando, pois, que essas etnografias "não fala pelos outros, mas sobre eles" (COMARROF; COMARROF, 2010, p. 12). Isso porque atenta-se para compreender as experiências do vivido pelo grupo, respeitando a dialética espaço-tempo na construção da identidade e dos significados tecidos.

Significados esses que precisam ser interpretados segundo o que o grupo pensa sobre suas práticas e construções simbólicas e materiais uma vez que "toda atividade humana é, ao mesmo tempo, material e simbólica, produção e comunicação" (COSGROVE, 2007, p. 130).

\section{ESPAÇO VIVIDO: FORMA E SIMBOLOGIA}

Na Geografia, a despeito da importância aos monumentos atribuída, o estudo foi tardio. Assim, "é no âmbito de uma Geografia cultural renovada, crítica e centrada nos significados atribuídos à natureza e às construções humana, que aparecem estudos de geógrafos discutindo os significados atribuídos aos monumentos" (CORRÊA, 2008, p. 9).

Pensando assim, "a análise geográfica deve examinar o espaço como um texto, onde formas são portadoras de significados e sentidos" (GOMES, 2010, p. 38). Logo, tem-se neste exame o monumento Araruna como forma e o espaço como texto dessa forma evidenciando, pois, forma e espacialidade da cultura Araruna.

Para Corrêa (2008, p. 11) "a análise geográfica dos monumentos pode estar centrada em dois focos principais, quais sejam, identidade e poder. Ambos manifestam-se de diferentes maneiras, entre elas, por intermédio dos monumentos". No caso em tela, a identidade revelada nesse lugar de simbolismo pelo qual a cultura ganha materialidade e as percepções sobre o espaço de vivência nesse locus, são carro-chefe no exame.

A forma espacial Araruna, na obra editada pelo SESC/RN em homenagem ao centenário do Mestre Cornélio Campina (1908-2008) intitulada de Araruna - Sociedade de Danças Antigas e Semi-Desaparecidas: orgulho e patrimônio cultural do $R N$, é possível identificar a elucidação de que:

A idéia de criar uma sociedade musical partiu de uma animada e elogiada quadrilha junina, criada e organizada pelo mestre Cornélio Campina e outros valorosos companheiros residentes no bairro das rocas, em meadas de 1949. As

\footnotetext{
${ }^{1}$ Entrevista concedida por A. M. M., 16 anos, no dia 09 de Agosto de 2012, em Natal/RN.

${ }^{2}$ Entrevista concedida por M. M. A., (não quis informar idade), no dia 09 de Agosto de 2012, em Natal/RN.
} 
reuniões e ensaios ocorriam em sede provisória na Rua Lucas Bicalho, residência do mestre, e outros ensaios aconteciam em frente à referida casa (SESC/RN, 2008, p. 65).

Ainda segundo o SESC/RN (2008, loc. cit.), "o prédio foi construído mediante trabalho voluntário dos próprios sócios fundadores e entregue à comunidade no ano de 1961". Localizada no bairro das Rocas, na Rua Mira Mar de esquina com a Rua Belo Horizonte, hoje (ver Figura 3), a sede, monumento pelo qual a cultura Araruna ganha materialidade no espaço, apresenta-se com uma infraestrutura precária, mais resiste às agressões do tempo e da carência de investimentos.

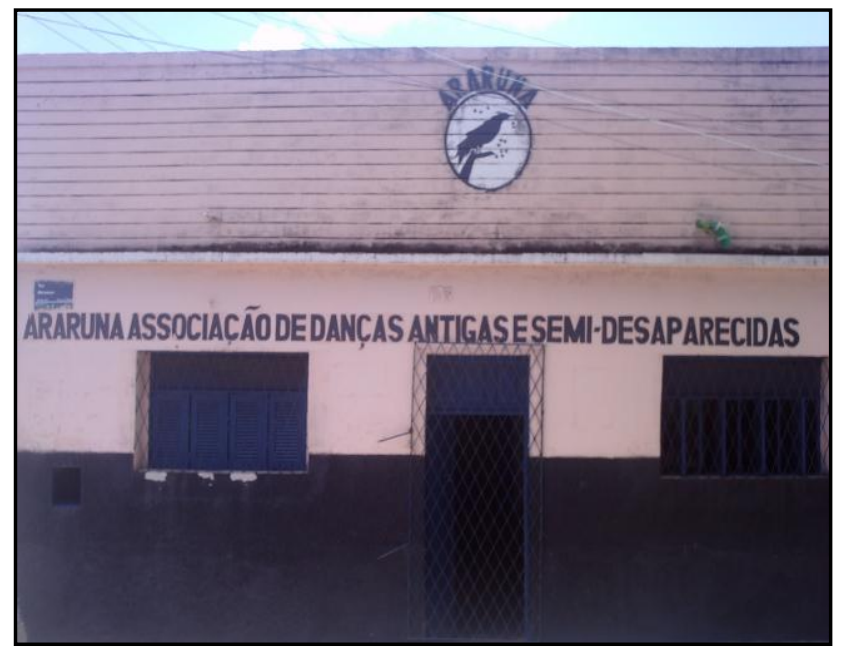

Figura 3 - Monumento cultural Araruna. Fonte: Martins (2011)

Suas reformas continuam contanto com o apoio de seus sócios. Exemplo contemporâneo foi a reforma do telhado datada de 29 de Março de 2011 por eles executada. O que permite inferir, de certo modo, que a forma espacial foi organizada e tratada com zelo e carinho pelos sócios, dirigentes e comunidade, qualificando a ideia de que "nos monumentos estão inscritos as representações que os homens fazem da história e da geografia. São eles, portanto, parte da complexa e variável temporalidade e espacialidade que caracterizam a ação humana" (CORRÊA, 2008, p.26).

Tratada neste estudo como forma espacial, monumento pelo qual a cultura e o grupo Araruna ganham materialidade no espaço, sua apreensão também pode se dá por meio de seu entendimento como patrimônio. Isso porque

Para versar sobre essa questão, a noção de patrimônio cultural ou histórico é mais comumente mobilizada. De um ponto de vista geográfico, o patrimônio tem uma localização ou uma inscrição espacial, mesmo no caso do patrimônio "imaterial". Nesse sentido, ele corresponde à expressão concreta do trabalho de memória que fazem as sociedades (BERDOULAY, 2012, p. 122).

Posto isso, tem-se então que da interação entre a cultura e o espaço Araruna emerge o lugar simbólico do grupo que este constrói ao mesmo tempo em que se constrói e constrói sua dinâmica, sua realidade vivida espacialmente. 


\section{MEMÓRIAS E EXPERIÊNCAIS DO ESPAÇO VIVIDO}

O olhar geográfico indica projeções de memórias e de experiências da prática cultural Araruna no espaço. De tal forma que ambas impregna-o e o incorporam sob a forma do vivido que lhe é próprio. Nesse sentido, o grupo cultural se identifica e se conhece nesse locus:

Cresci inserido dentro da Araruna. Desde a minha infância que minha vida é Araruna. Foi meu lazer na época, nasci e me criei nela. [...] faz parte de minha identidade. Lá (se referindo à forma espacial) ganhei minha esposa, a conquistei nos ensaios da dança. A minha primeira dama na dança que continua até hoje (Informação verbal) ${ }^{3}$.

Esses reconhecimentos, de certo modo, revelam que o acontecido é parte integral da própria memória que também constitui as experiências dos sujeitos. Isso é também muito evidente na afirmativa: "não tem como eu não me identificar com a Araruna, nem ela a mim. Faz parte de mim e eu dela. Fico feliz. Grato por divulgar a cultura que faz parte de mim" (Informação verbal) ${ }^{4}$. Dessa forma, os atores sociais apresentam plena consciência sobre a prática cultural que, em grande medida, funciona como fonte de identificação e significação espaço-cultural. A tal ponto que: "Mesmo estando num leito de hospital, sinto que preciso melhorar para dançar a Araruna. Mim sinto bem nela quando danço. Enquanto puder continuarei dançando porque faz parte de minha vida" (Informação verbal) ${ }^{5}$.

Dessa forma, infere-se que há existência de sentimentos de pertencimentos, eminentes à cultura que rebate a construção de identidades. Identidades essas que remetem ao espaço, que se materializam na forma espacial e que identificam o grupo. Dessa forma, é fonte de significação e identificação:

Minha principal área de lazer. Uma segunda casa. Da minha casa para lá (referindo-se a forma espacial Araruna), de lá para minha casa. Quando minha mãe me perguntava, quando eu era pequeno, onde eu estava, eu respondia que lá estava. Eu dizia: não foi lá que me criei mãe! (Informação verbal). ${ }^{6}$

Nessa perspectiva, tem-se então a revelação de significados concedidos ao espaço vivido pelo grupo na tradução das experiências de forma que essas significâncias resultam das relações tempo-espaço-vivência.

Desponta nas falas dos atores sociais ainda a preocupação dos integrantes em manter o prédio em permanente manutenção. Para M. C. B. N., por exemplo, tanto a forma espacial quanto a manifestação cultural do grupo constituem "um pilar de cultura que acredito que pode ser ruído (corroído) com o tempo se não dedicamos a atenção merecida, se não tiver incentivo, apoio. Lugar de encontro!" (Informação verbal) ${ }^{7}$. Nesse sentido, prevalece a certeza de que o tempo implacável pode contribuir para o desaparecimento do mesmo.

\footnotetext{
${ }^{3}$ Entrevista concedida por F. A., 35 anos, no dia 09 de Agosto de 2012, em Natal/RN.

${ }^{4}$ Entrevista concedida por M. C. B. N., 30 anos, no dia 09 de Agosto de 2012, em Natal/RN.

${ }^{5}$ Entrevista concedida por P. F. R., 56 anos, no dia 29 de Março de 2012, em Natal/RN.

${ }^{6}$ Entrevista concedida por F. A., 35 anos, no dia 09 de Agosto de 2012, em Natal/RN.

${ }^{7}$ Entrevista concedida por M. C. B. N., 30 anos, no dia 09 de Agosto de 2012, em Natal/RN.
} 
Dessa forma, as acepções são diversas mais todas revelam, seja naquele que integra o grupo há mais tempo (P. F. R., 56 anos), seja no que integra há menos tempo (A. M. M. 16 anos), os significados atribuídos são evidentes e traduzem suas sensações e experiências para com o espaço e cultura e destes para com eles. Tão evidente que, mesmo estando em leito de hospital, o pertencimento e o desejo de manter a cultura, permanece consciente e intacto no integrante $P$. F. R (56 anos).

Assim, acredita-se que os significados não são apenas um produto social do grupo Araruna em particular e/ou das sociedades em geral, pois eles constituem também uma condição para a reprodução social, incluindo não apenas valores, crenças, mitos e utopias, mas também as relações sociais e a espacialidade do grupo, da humanidade, ou seja, uma condição para reprodução de uma realidade vivida espacialmente (CORRÊA, 2009).

Espacialidade essa construída no tempo e no espaço e revelada na manifestação cultural do grupo. Seja a manifestação da cultura por meio da forma espacial, seja ela por meio dos significados atribuídos e da identidade construída no espaço de vivência.

Espaço esse que, frequentemente, corresponde à área de manifestação da cultura. Composto pelo entrelaçamento do grupo com a forma espacial e a manifestação que ali se constrói, mas que repercute num quadro maior: cidade, estado, país. Carregado de afetividades que, paralelo ao que Gallais (1977) havia dito, esta afetividade não é apenas constituída pela amizade que os homens (o grupo) nutre $(\mathrm{m})$ naturalmente pela região e pelo tipo de meio em que cresceram, mas é também reforçada pela movimentação do espaço, verdadeiro interlocutor. Espaço "vivido não em sua positividade, mas com todas as parcialidades da imaginação" (BACHELARD, 1998, p.19). Um espaço que não está entregue à mensuração, ao consumo.

Por tudo isso, é fornecido e interpretado um quadro da realidade vivida espacialmente pelo grupo em meio às teias de significados construídas e tecidas na cultura Araruna, caracterizada pelo entrelaçamento desta cultura com seus atores construtores e destes como a forma espacial, com a qual no espaço de sua manifestação eles revelam identidade e os significados atribuídos e resignificados.

Nesse quadro, a memória cumpre fundamental papel ao passo que povoa as subjetividades e resgata experiências do vivido, das lembranças. Consiste, pois, no "momento de desempenhar a alta função da lembrança. Não porque as sensações se enfraquecem, mas porque o interesse se desloca, as reflexões seguem outra linha e se dobram sobre a quintessência do vivido" (BOSI, 1994, p. 81) revelando os significados que a cultura propicia à existência do grupo. Dessa forma, qualificando as realidades apresentadas nas etnografias no contexto do espaço de manifestação da cultura Araruna. Espaço esse que, como visto, traduz o mais íntimo de sua cultura.

Pensando assim, a busca, no sentido simbólico, de significados e identidade na cultura Araruna revela elementos que retratam a identificação social do grupo pressupondo, nos resultados, certa dialética na construção destes. Já havia alertado Castells (1999) na sua obra $O$ Poder da Identidade que o entendimento da identidade perpassa sua construção tendo como fonte o significado e a experiência de um povo.

Por tudo, tem-se então que o estudo em tela se vale da matéria-prima fornecida pela história, geografia, antropologia para explicar os significados e a identidade construída no grupo Araruna. 
Pensando assim, o locus do vivido é um celeiro propício para se construir experiências, memórias, práticas e atribuí-lhes significados por dado grupo social ao mesmo tempo que revelaos, impregna-os, torna-se manifestação da cultura povoado de simbologia e subjetividades construídos no espaço e no tempo. Dessa forma, podendo ser compreendido na acepção de que o espaço vivido é um espaço-movimento e um espaço-tempo vivido (FRÉMONT, 1980).

\section{CONCLUSÃO}

"Para não concluir" parece uma frase oportuna a este estudo. Isto porque o trabalho revela percepções da dimensão cultural do espaço vivido do grupo Araruna traduzida nas realidades vividas espacialmente e sendo manifestada na identidade e nos significados que este atribuí ao seu espaço, ou seja, na prática cultural Araruna que indica ao olhar geográfico uma dimensão espacial.

Pensado assim, apresenta-se conclusões do que se propôs pesquisar, no entanto tem-se a certeza de que a pesquisa não para por aqui, uma vez que o trabalho não esta isento de críticas. Por ser um texto, um recorte analítico de uma realidade vivida espacialmente, pode adquirir múltiplas interpretações e ser lhe atribuído diferentes significações, o que the confere dinamicidade e abertura para contribuições.

$\mathrm{Na}$ ordem do que se propôs pesquisar, a problemática é chamada à baila para direcionar as considerações subsequentes: qual a dimensão cultural do espaço vivido do grupo Araruna? As respostas que o trabalho oferece estão pautadas nas subjetividades, nas (i) materialidades do grupo manifestadas na cultura Araruna e traduzidas no patrimônio, na história, nas espacialidades, na identidade e nos significados pelo grupo atribuídos ao espaço. Tudo tecido na realidade vivida espacialmente no decorrer dos 56 anos de tradição do Araruna onde as práticas, ações e memórias são trazidas às compreensões e apreensão da tessitura construída no processo constate de construção e reconstrução espaço-cultural que configura o arranjo espacial da realidade do grupo.

Nesse contexto, o grupo constrói formas de identificação com o espaço reveladas nos sentimentos e significados atribuídos a este e, sua espacialidade transcende o espaço vivido de base identitária e se propaga nas manifestações na cidade, no estado e no país.

Por tudo, pode-se constatar que a representação espacial da realidade vivida pelo grupo se apresenta na forma de monumento, forma espacial traduzida na sede do grupo que materializa parte de sua cultura e constitui base de sua identidade. Dessa forma, qualificando-se como um espaço dotado de memória, valores, sentimentos, significados, onde as vivências e experiências são articuladas, constituindo-se, pois, como foco inicial (hearth), lugar de onde origina-se e parte a difusão da espacialidade Araruna.

Visto isto, tem-se que o grupo tanto pode construir seu mundo real como imagético na sua prática sócio-espaço-cultural. E esse mundo tem revelado um movimento que aponta construções e reconstruções de suas práticas, caracterizando um processo em curso, em meio à dinâmica espaço-tempo-vivência, que sustenta a vida e lhes confere sentido.

Nesse contexto, o trabalho dar evidência a ideia de que muitas leituras do espaço são possíveis e concorda que nenhuma é superior à outra uma vez que cada uma revela uma faceta da multiplicidade desse objeto de investigação. 


\section{REFERÊNCIAS BIBLIOGRÁFICAS}

1. BACHELARD, Gaston. A formação do espírito científico: contribuição para uma psicanálise do conhecimento. Rio de Janeiro: Contraponto, 1996.

2. . A poética do espaço. São Paulo: Editora Martins Fontes, 1998.

3. BARTH, Fredrick. A análise da cultura nas sociedades complexas. In: (Org.). 0 guro e o iniciador e outras variações antropológicas. São Paulo: Abril Cultural, 2000. p. 107-140.

4. BERDOULAY, Vincent. Espaço e cultura. In: CASTRO, Iná Elias de; GOMES, Paulo Cesar da Costa; CORRÊA, Roberto Lobato (Orgs). Olhares geográficos: modos de ver e viver o espaço. Rio de Janeiro: Bertrand Brasil, 2012. p.101-131.

5. BOSI, Ecléa. Memória e sociedade: lembranças de velhos. 3. ed. São Paulo: Companhia das Letras, 1994.

6. CASCUDO, Luiz da Câmara. Antologia do folclore brasileiro. 2. ed. São Paulo: 1954.

7. CASTELLS, Manuel. O poder da identidade. São Paulo: Paz e Terra, 1999.

8. COMARROFF, Jean; COMARROFF, John. Etnografia e imaginação histórica. Revista Proa, n. 02, vol. $01, \quad$ p. $\quad 1-72 ~ 2010 . \quad$ Disponível em: <http://www.ifch.unicamp.br/proa/Traducoesll/pdfs/comaroff.pdf>. Acessado em 22 de setembro de 2012.

9. CORRÊA, Roberto Lobato. Monumento e geografia: uma sistematização. In: DANTAS, Aldo (Org.). Geografia e cultura, marxismo, complexidade, ensino, planejamento, saúde. Natal: EDUFRN, 2008. p. 9-29.

10. . Sobre a geografia cultural. INSTITUTO HISTÓRICO GEOGRÁFICO DO RIO GRANDE DO SUL. Contribuições. Porto Alegre: IHGRS, 2009. Disponível em: < http://www.ihgrgs.org.br/Contribuicoes/Geografia_Cultural.htm > Acessado em 23 de setembro de 2012.

11. CORRÊA, Roberto Lobato; ROSENDAHL, Zeny. Geografia cultural: introduzindo a temática, os textos e uma agenda. In: (Org.). Introdução à geografia cultural. 3. ed. Rio de Janeiro: Bertrand Brasil, 2010. p. 9-26.

12. COSGROVE, Denis. Em direção a uma geografia cultural radical: Problemas da Teoria. In: CORRÊA, Roberto Lobato; ROSENDAHL, Zeny. Introdução à geografia cultural. Rio de Janeiro: Bertrand Brasil, 2007. p.104-134

13. CLAVAL, Paul. As abordagens da geografia cultural. In: CASTRO, Iná Elias; GOMES, Paulo C. da Costa; CORRÊIA, Roberto Lobato (Orgs.). Explorações geográficas. 4. ed. Rio de Janeiro: Bertrand Brasil, 2010. p. 89-117.

14. FRÉMONT, Armand. A região, espaço vivido. Coimbra: Almedina, 1980.

15. GALLAIS, Jean. Alguns aspectos do espaço vivido nas civilizações do mundo tropical. Boletim Geográfico, Rio de Janeiro, v. 35, n. 254, p. 5-13, 1977.

16. GEERTZ, Clifford. A interpretação das culturas. Rio de Janeiro: Zahar Editores, 1978.

17. GIL, Antônio Carlos. Métodos e técnicas de pesquisa social. 5. ed. São Paulo: Atlas, 1999. 
18. GOMES, Paulo Cesar da Costa. Geografia fin-de-siècle: o discurso sobre a ordem do mundo e o fim das ilusões. In:CASTRO, Iná Elias; GOMES, Paulo C. da Costa; CORRÊA, Roberto Lobato. Explorações geográficas. 4. ed. Rio de Janeiro: Bertrand Brasil, 2010. p. 13-42.

19. GURGEL, Deífilo. Danças folclóricas do Rio Grande do Norte. 2. ed. Natal: UFRN, Editora Universitária, 1982.

20. Espaço e tempo do folclore potiguar. 3. ed. Natal: Governo do Estado do Rio Grande do Norte, Departamento Estadual de Imprensa, 2001.

21. HAESBAERT, Rogério. Territórios alternativos. 2. ed. São Paulo: Contexto, 2006.

22. HUSSERL, Edmund. La idea de la fenomenologia: cinco lecciones. México: Fondo de Cultura Econômica, 1982. Disponível em: <http://pt.scribd.com/doc/27798018/Edmund-Husserl-LaIdea-de-la-Fenomenologia > Acessado em 05 de Maio de 2012.

23. MACEDO, Helder Alexandre Medeiros de. $\mathbf{O}$ que é patrimônio imaterial?. Projeto Patrimônio Cultural Potiguar em 6 Tempos. UNESCO/MINC/BID. Natal: Fundação José Algusto, 2006a.

24. Levantamento do patrimônio imaterial do Rio Grande do Norte. Projeto Patrimônio Cultural Potiguar em 6 Tempos. UNESCO/MINC/BID. Natal: Fundação José Algusto, 2006b.

25. MALINOWSKI, Bronislaw Kasper. Argonaltas do pacífico ocidental. 2. ed. São Paulo: Abril Cultural, 1978.

26. MARCONI, Maria de A.; LAKATOS, Eva Maria. Metodologia científica. 4. ed. São Paulo: Atlas, 2004.

27. MARTINS, Josenildo da Silva. Fotografias de estudo de campo. 2011. 6 Fotografias.

28. MAY, Tim. Pesquisa social: questões, métodos e processos. Porto Alegre: Artmed, 2004.

29. NOGUEIRA, Narciso Lopes. Natal e seu folclore: Araruna. Natal: Sociedade Araruna, 1978.

30. RELPH, Edward. As bases fenomenológicas da geografia. Geografia, Rio Claro, v.4, n.7, p.1-25, 1979.

31. SERPA, Angelo Szaniecki Perret. Lugares enunciados, lugares comunicados: processos identitários em Berlim e Salvador. Geograficidade. Rio de Janeiro, v. 2. n. 2, p. 40-49. inverno de 2012.

32. SERVIÇO SOCIAL DO COMÉRCIO DO RIO GRANDE DO NORTE (SESC/RN). Sociedade de Danças Antigas e Semi-Desaparecidas: orgulho e patrimônio cultural do RN. Jackeline Pinheiro Maia Cavalcanti (Coord.). Natal: SESC/RN, 2008. 